\title{
A RELEVÂNCIA DA ELIMINAÇÃO DO DESPERDÍCIO: UM ESTUDO DE CASO EM UMA EMPRESA DE TECELAGEM
}

\author{
Jessica Freire Moreira \\ Universidade Católica de Petrópolis \\ Jeje_freire@hotmail.com
}

\begin{abstract}
RESUMO
Hoje em dia, a produtividade está relacionada diretamente com a organização e as condições de trabalho e treinamento de sua mão de obra. O trabalho a seguir faz a análise do processo produtivo de uma Empresa têxtil, principalmente, de atividades que geram altos índices de desperdício e acabam impactando a sua produção e, com isso, seu lucro. Este estudo apresenta a análise feita nessa Indústria, onde são observados aspectos referentes ao processo de produção, organização do trabalho e meio ambiente. A partir dessa análise são feitas sugestões de melhorias, visando ao aumento da produtividade, melhorias nas condições de trabalho e reorganização de seus processos, com o fim de redução do desperdício. Reduzir desperdícios significa reduzir, entre outros, custos, tempo, movimentação, transportes desnecessários, ou seja, reduzir tudo aquilo que não agrega valor ao produto final fabricado. O que permite garantir melhor qualidade, redução de estoque, maior segurança à saúde do colaborador e, com isso, preços mais justos.
\end{abstract}

Palavra-chave: Desperdício; Redução; Tecelagem.

\begin{abstract}
Today, a student is directly qualified with an organization and working conditions and training of his workforce. The following work analyzes the production process of a textile company, especially activities that generate high waste rates and end up impacting its production and, thus, its profit. This study presents an analysis made in this industry, where aspects related to the production process, work organization and environment are observed. From this analysis, suggestions are made for improvement, monitoring of performance increase, improvements in working conditions and reorganization of their processes, in order to reduce waste. Reducing waste means reducing, among others, unnecessary costs, time, movement, transportation or reducing anything that does not add value to the final product manufactured. This enables better quality, reduced inventory, greater health security for the employee and, with it, fairer prices.
\end{abstract}

Keywords: Waste; Reduction; Weaving.

\section{Como Citar:}

MOREIRA, Jessica Freire. A relevância da eliminação do desperdício: um estudo de caso em uma empresa de tecelagem. In: SIMPÓSIO DE PESQUISA OPERACIONAL E LOGÍSTICA DA MARINHA, 19., 2019, Rio de Janeiro, RJ. Anais [...]. Rio de Janeiro: Centro de Análises de Sistemas Navais, 2019. 


\section{INTRODUÇÃO}

Com a existência atual de alto grau de competitividade entre as empresas, evitar o desperdício para reduzir custos e tempo tornou-se um dos tópicos principais em discussões. O estágio avançado da tecnologia possibilita uma enorme variedade de ferramentas para que se aumente o índice de aproveitamento dos materiais. Com isso, o modelo Toyota de produção surge no Japão e, por volta da década de 50, começa a ser aplicado. Ele preza pelo aumento da eficiência, da eficácia e da produtividade, evitando esperdícios, eliminando não conformidades e problemas industriais, principalmente ligados ao estoque (HIRANO, 1989).

O objetivo deste estudo é a redução das perdas em uma empresa de tecelagem seguindo a filosofia do Sistema Toyota de Produção, que trata da eliminação completa de todos os tipos de desperdícios, em todas as fases da produção, buscando métodos mais eficientes. Essa filosofia produtiva ficou conhecida como "Sistema de Produção Enxuta" (HIRANO, 1989). O STP, também conhecido por Produção Enxuta ou Lean Manufacturing, foi criado no Japão após a Segunda Guerra, com o objetivo da redução e/ou eliminação de esperdício dentro dos processos de produção, tendo como estratégia a otimização dos processos e o mapeamento de fluxo de valor (ISERHARD, 2013; MORAES et al., 2011).

O sistema Toyota de Produção foi escolhido como modelo, visto que é o modelo de uma companhia com um número quase nulo de desperdícios e um exemplo para todas as indústrias ao redor do mundo. Procuram-se propor soluções de rearranjo, redução de transporte e movimentos, uma reestruturação das atividades, entre outras propostas, visando à eliminação de qualquer fonte de desperdício que possa provir de atividades que não gerem valor agregado ao produto final. As melhorias propostas visam a alcançar o ambiente ideal de trabalho, mantendo os interesses dos funcionários e da Indústria. Para o STP, a inspeção é fundamental para a eliminação das perdas por produtos defeituosos. É importante destacar que a inspeção deve ser realizada não só com o objetivo de encontrar os defeitos, mas também preveni-los (DRESCH, DIENSTMANN, CASSEL, 2011).

Segundo Slack, Chambers e Johnston (2002), na Toyota, produzir mais do que é necessário para o próximo processo na produção é a maior das fontes de desperdício. Logo, um controle do estoque é primordial para todas as indústrias, independente do ramo. Neste estudo, são apresentadas ideias de métodos para se obter um melhor controle de estoque e será exposta uma nova organização do espaço atual, visto que, atualmente, a matéria-prima é armazenada juntamente com o produto acabado. 
De acordo com Iida (2002), a curta duração dos ciclos de trabalho pode gerar a monotonia, causando a falta de atenção. Se o colaborador passar o seu tempo de trabalho inteiramente ocupado com apenas uma função, podemos garantir uma maior concentração nessa determinada função. Neste estudo, a proposta é reorganizar os funcionários para que todos estejam sempre ocupados, com isso será necessário implementar dispositivos nas máquinas.

Com as explicações supracitadas, encontram-se neste artigo as respostas para as seguintes perguntas:

Pergunta 1: Quais as formas diferentes de desperdício em materiais, mão-de-obra, espaço físico, estoque ou transporte, observados na Empresa estudada?

Pergunta 2: Quais as medidas necessárias para evitar os desperdícios atuando no processamento ou nas entradas e saídas?

\section{METODOLOGIA}

Foi utilizado o método de pesquisa-ação com a finalidade de analisar os problemas enfrentados em uma empresa de tecelagem local, partindo de uma revisão bibliográfica. A finalidade foi traçar uma estratégia que possa ser trabalhada como exemplo e aplicada junto ao estudo de caso. Este estudo possui características quantitativas e qualitativas, com ênfase na observação e estudo documental, ao mesmo tempo em que foi necessário o cruzamento dos levantamentos com toda a pesquisa bibliográfica feita, necessitando de pesquisas documentais e entrevistas com os responsáveis pelo espaço e com os operadores das máquinas, tendo como base relatórios técnicos e artigos científicos. A parte financeira não foi levada em consideração neste estudo. Este estudo tem como característica uma pesquisaação, que é definida como uma pesquisa com base empírica que é realizada em conjunto com uma busca para solução dos problemas apresentados e na qual os pesquisadores e os colaboradores da empresa se envolvem em caráter cooperativo ou participativo.

O estudo de caso nasceu da necessidade de criar uma proposta para a redução dos desperdícios em uma fábrica de pequeno porte, localizada na cidade de Petrópolis. Havia uma enorme quantidade de tipos de desperdício no processo de produção que eram ignorados por falta de conhecimento sobre Produção Enxuta. Não existia ergonomia, o estoque era feito de caixas empilhadas sem nenhum tipo de organização, rejeitos de algodão voavam por todo o setor de produção e o maquinário era antigo e sem sensores e equipamentos que trariam um maior rendimento para a indústria. 
Com base nos dados apresentados anteriormente, etapas foram definidas para este trabalho. Inicialmente, coletaram-se dados pertinentes à produção além de terem sido feitos os registros e as anotações necessárias, a partir dos quais foi elaborado o fluxograma da produção, com o intuito de melhorar o entendimento, servir como base para um estudo sobre os melhores sistemas de produção e ter uma visão de como funcionam tais sistemas. Através da análise do fluxograma, foi possível verificar as perdas no processo, analisando as mesmas e, assim, classificá-las de acordo com as perdas do Sistema Toyota de Produção. Posteriormente, prosseguiu-se na análise dos dados coletados e no apontamento dos problemas que mais afetavam a produção e que deveriam ser tratados imediatamente, através da aplicação de ferramentas de qualidade. Houve uma pesquisa por sensores e equipamentos de controle para serem incorporados aos teares circulares e práticas em indústrias similares ou em que existiam problemas parecidos com os encontrados.

\section{ESTUDO DE CASO}

A figura 1 apresenta um diagrama do processo de fabricação atual:

Figura 1 - Diagrama do processo de fabricação atual

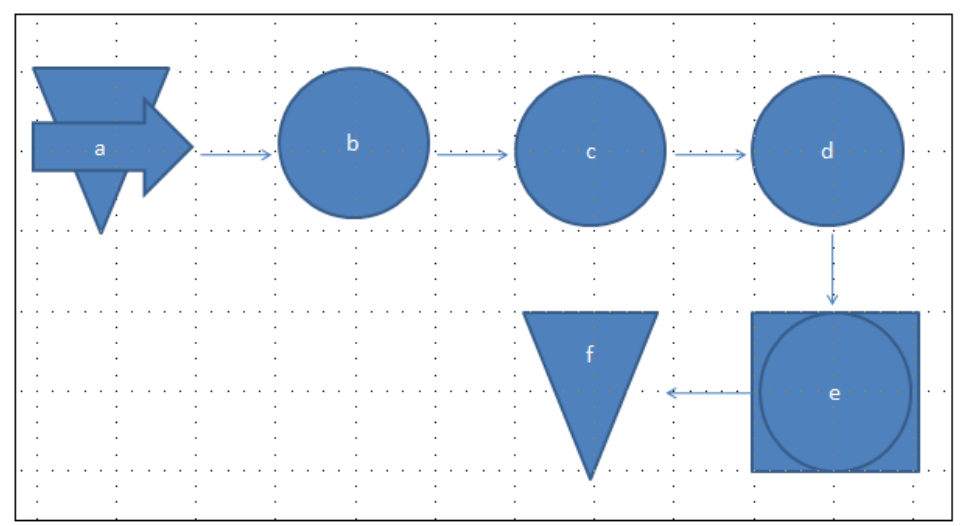

FONTE: A autora (2018).

Pode-se descrever este processo como:

a) Chegada e estocagem da matéria-prima: a entrada de matéria-prima é feita de forma manual, colocam-se as caixas com os fios empilhados para serem levadas ao estoque. O estoque é armazenado sem levar em consideração a ordem de chegada e saída da matéria prima e é organizado junto com o material já produzido;

b) Preparação da máquina de tecelagem: ocorre a colocação da agulha na linha de ar, processo que ocorre de forma manual pelo próprio operador daquela 
máquina. Não é levado em consideração qual fio está armazenado há mais tempo no estoque;

c) Colocação do fio na agulha: a colocação de cones é feita de forma manual pelo operador da máquina;

d) Produção do tecido: operação realizada pela máquina com a supervisão de um operador para cada duas máquinas. A limpeza da máquina após a produção é de responsabilidade do operário;

e) Pesagem, inspeção e identificação: após a finalização da fabricação do tecido, o rolo é transportado manualmente para a pesagem e a identificação é feita pelo próprio operador da máquina;

f) Estocagem do produto acabado: após a identificação, o produto final é levado para o estoque.

O tempo gasto por cada funcionário neste processo de produção atual é observado na tabela 1, deve-se levar em consideração que o tempo foi medido por meio de um cronômetro.

Tabela 1 - Diagrama homem-máquina de um operário em relação às máquinas em tempo aproximado

\begin{tabular}{|c|c|c|c|c|c|}
\hline \multicolumn{6}{|c|}{ Gráfico Homem-máquina } \\
\hline Homem & Tempo & Máquina 1 & Tempo & Máquina 2 & Tempo \\
\hline Colocação dos fios & $10 \mathrm{~min}$ & Colocação dos fios & $10 \mathrm{~min}$ & Espera & $10 \mathrm{~min}$ \\
\hline Colocação dos fios & $10 \mathrm{~min}$ & Espera & $10 \mathrm{~min}$ & Colocação dos fios & $10 \mathrm{~min}$ \\
\hline Inspeção visual das máquinas & $60 \mathrm{~min}$ & Fabricação & $60 \mathrm{~min}$ & Fabricação & $60 \mathrm{~min}$ \\
\hline Transporte & $20 \mathrm{~min}$ & Espera & $20 \mathrm{~min}$ & Espera & $20 \mathrm{~min}$ \\
\hline Inspeção & $30 \mathrm{~min}$ & Espera & $30 \mathrm{~min}$ & Espera & $30 \mathrm{~min}$ \\
\hline Limpeza & $30 \mathrm{~min}$ & Espera & $30 \mathrm{~min}$ & Espera & $30 \mathrm{~min}$ \\
\hline Estocagem & $10 \mathrm{~min}$ & Espera & $10 \mathrm{~min}$ & Espera & $10 \mathrm{~min}$ \\
\hline
\end{tabular}

FONTE: A autora (2018).

Com isso foram identificados os seguintes problemas mostrados na figura 2, dos quais serão estudadas propostas de apenas uma parte deles:

Figura 2 - Diagrama de Ishikawa para a determinação dos problemas relacionados ao desperdício

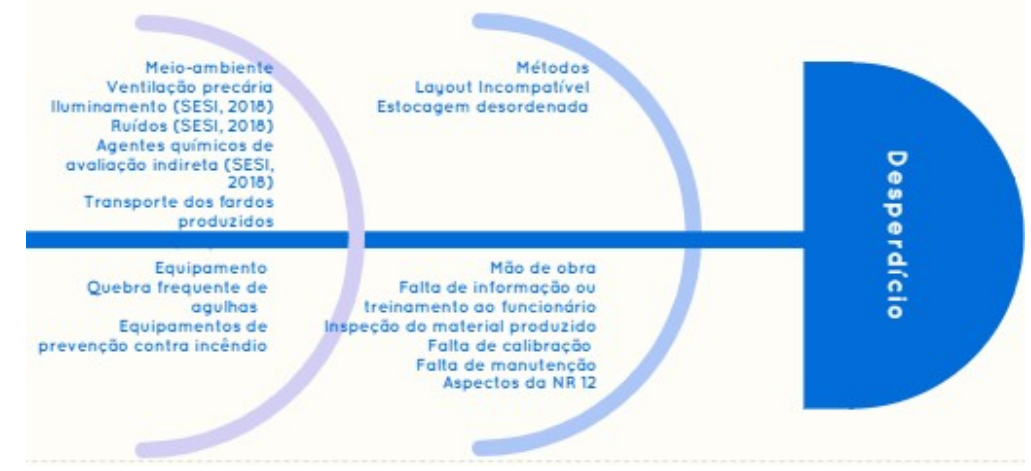

FONTE: A autora (2018). 
Para a interpretação do diagrama, deve-se levar em consideração a seguinte explicação das divisões:

a) Meio ambiente: dificuldades no sistema produtivo podem causar problemas físicos ao colaborador, além do mais podem gerar falhas no material produzido;

b) Métodos: problemas pela falta de organização do ambiente produtivo;

c) Equipamento: problemas ligados à falta de equipamentos mais modernos para a atividade ou à falta de equipamentos de segurança;

d) Mão de obra: problemas gerados pela má gestão de pessoas, como a falta de informação ou de treinamento ao funcionário.

Analisando o ambiente de trabalho e o processo de produção, constatou-se que são os próprios operários que fazem a limpeza das máquinas. Segundo estudos, a indústria têxtil está entre as profissões mais perigosas para o sistema respiratório humano. Sempre há uma grande quantidade de resíduos de algodão pela área produtiva, tanto no chão quanto no ar, como pode ser observado na figura 3. São fornecidos EPI’s (como máscaras, protetores auriculares e botas), porém não são utilizados pelos colaboradores, pois os mesmos dizem que geram desconforto.

Figura 3 - Resíduos de algodão espalhados pelo chão da área produtiva

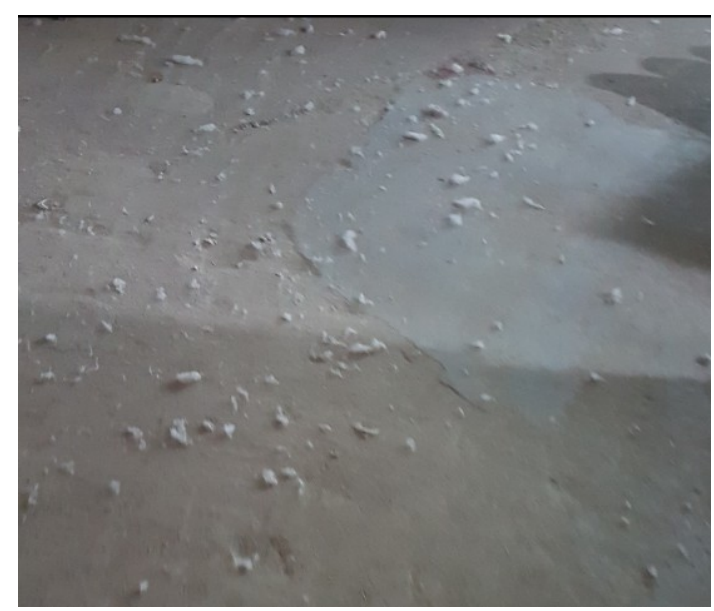

FONTE: A autora (2018).

O produto acabado é carregado manualmente e individualmente. Além disso, a matéria-prima é estocada junto com o produto acabado, lixos e os produtos defeituosos como demonstrado na figura 4. 
Figura 4 - Representação da estocagem

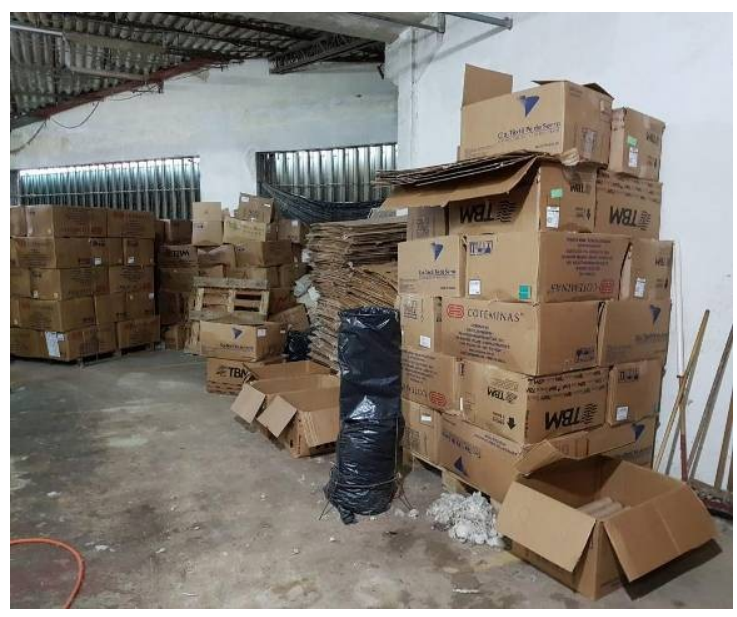

FONTE: A autora (2018).

Analisando o preparo dos operários/procedimentos, notou-se que ocorre uma grande quantidade de quebra de agulhas, o que gera falhas no produto final. A limpeza é feita de forma manual, com mangueiras de água e vassouras. A cada duas máquinas, há um operador supervisionando-as. Caso ocorra a quebra de uma agulha e o operador não veja a tempo, gera-se a perda do material fabricado naquele ciclo. Também não há calibração nos instrumentos utilizados. A figura 5 retrata um cenário repetitivo: são três operários colocando fios em uma máquina, enquanto isso outras máquinas estão sem supervisão. Isso pode aumentar o número de quebras de agulhas e, com isso, gerar altos gastos desnecessários.

Figura 5 - Três operários colocando fios em uma máquina, enquanto outras máquinas continuam a funcionar sem supervisão

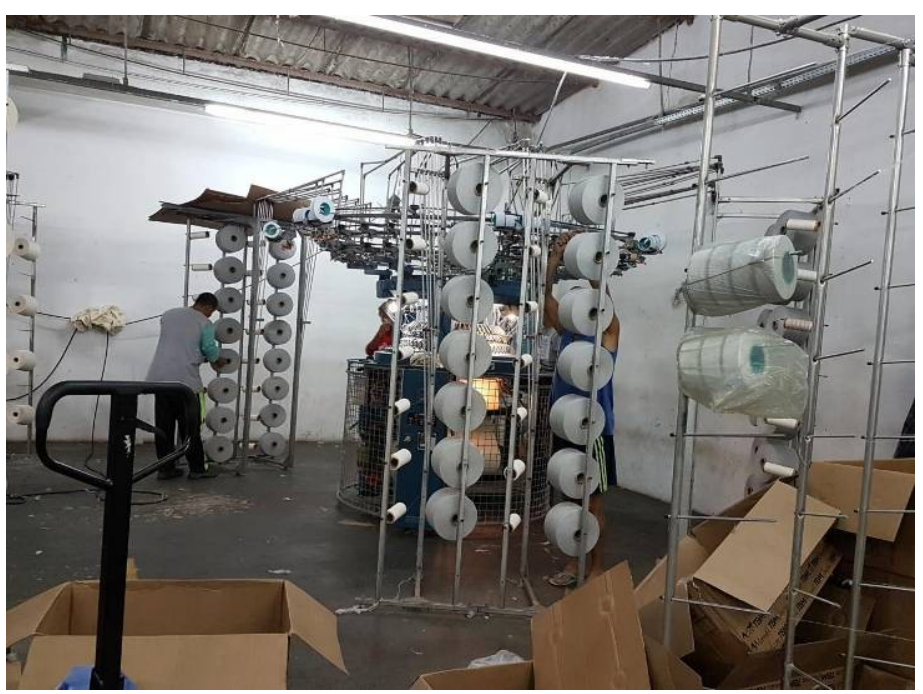

FONTE: A autora (2018). 


\section{SPOLM2019}

XIX SIMPÓSIO DE PESQUISA OPERACIONAL E LOGISTICA DA MARINHA RIO DE JANEIRO, RJ, BRASIL - 06 A 08 DE NOVEMBRO DE 2019

Analisando os processos produtivos, constatou-se que o processo apresenta uma série de problemas envolvendo o desperdício. Este tópico faz uma descrição do processo produtivo e tem por finalidade apresentar o cenário atual como forma de proporcionar um melhor entendimento da sua dinâmica e como os problemas observados se encontram inseridos.

No estudo, observaram-se os seguintes problemas e soluções:

\subsection{PROBLEMA 1 - AGENTES QUÍMICOS DE AVALIAÇÃO INDIRETA (SESI, 2018)}

São oito máquinas programadas para a produção de ribana (cento e trinta quilos em dez horas) e meia malha (cento e oitenta quilos em dez horas). No fim do processo produtivo, após a retirada do rolo de tecido da máquina, leva-se quinze minutos por máquina para realizar sua limpeza. O método para a limpeza é a utilização do ar comprimido, ou seja, o restante de algodão é espalhado no ar.

Contando o tempo desde o momento em que os resíduos são depositados no chão, umedecidos e varridos, obtemos um total de trinta minutos com a limpeza de uma máquina e mesmo assim não se obtém uma eficiência de cem por cento na limpeza. Na figura 6, é apresentada a forma que os funcionários deixam o ambiente produtivo após a limpeza de suas máquinas. Podemos perceber que os resíduos se mantêm no ambiente, não sendo jogados no lixo.

Figura 6 - Apresentação do ambiente produtivo após a limpeza das máquinas

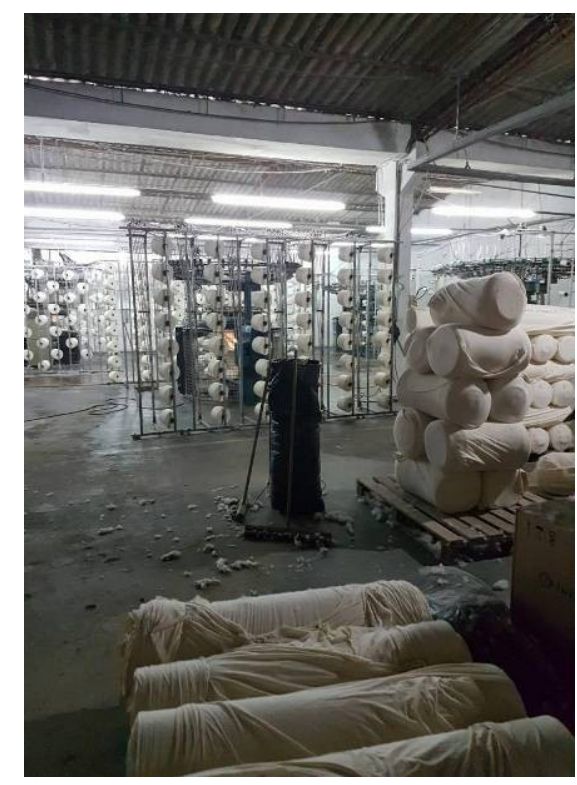

FONTE: A autora (2018).

A poeira do algodão é espalhada no ar em todo o momento de funcionamento das máquinas, ainda assim os operários não utilizam os equipamentos de segurança, mesmo 
sendo fornecidos pela empresa. O trabalho é realizado sem a colocação de máscaras; os empregados utilizam sandálias ao invés de botas, correndo o risco de causar acidentes de trabalho, como torcer o pé, uma vez que sandália não é o tipo de calçado apropriado para essa função. Outra ação inadequada é utilizar jatos de água próximos às tomadas de eletricidade, o que pode gerar riscos, como podemos ver na figura 7.

Figura 7 - Chão molhado perto de tomadas de eletricidade

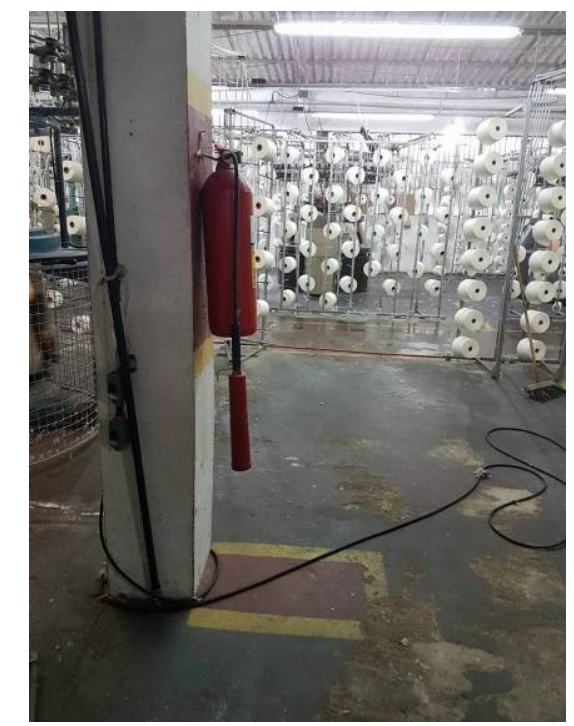

FONTE: A autora (2018).

Solução: Há no mercado Linhas Completas de sopro e aspiração para a limpeza automática de máquinas têxteis, aumentando, então, o índice de qualidade da malha e da eficiência do tear com menos quebra de agulhas. Na figura 8, pode-se observar um exemplo de uma máquina de sopro e aspiração recomendada.

Figura 8 - Exemplo de máquina de sopro e aspiração

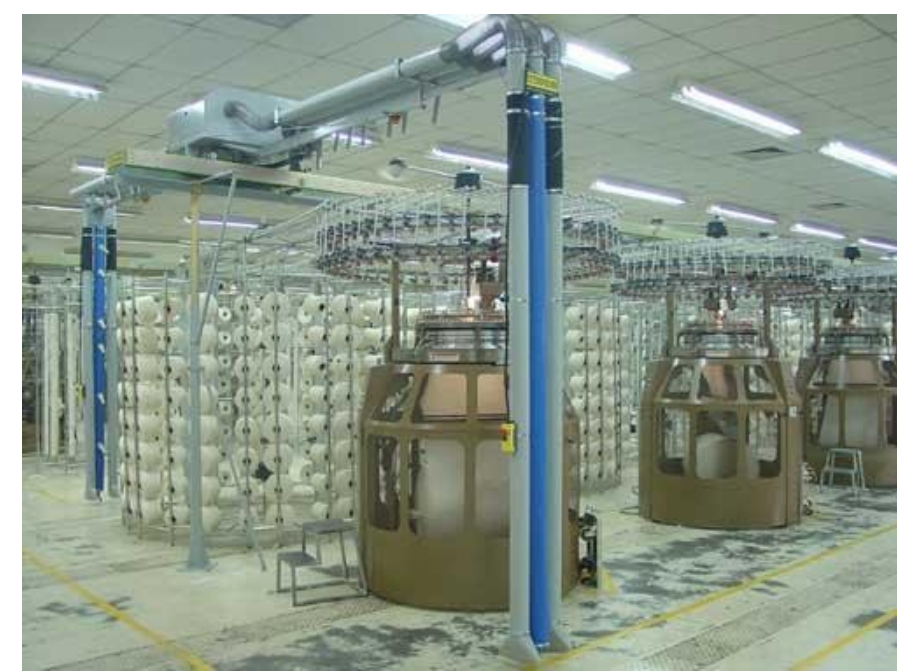

FONTE: Sopro e aspiração - limpadores viajantes: tear circular (2018). 
Descrição da máquina segundo o fabricante:

Após completar o ciclo de trabalho, o carro entra em um tubo de aspiração para descarregar as impurezas coletadas no processo e limpar o filtro. Este resíduo coletado automaticamente será conduzido através de tubulação a uma central de aspiração a ser instalada em uma das extremidades da sala. A Stemmann fabrica uma linha completa de aparelho de sopro e aspiração para limpeza automática de máquinas têxteis, como por exemplo Tear Circular, aumentado com isto o índice de qualidade da malha e eficiência do tear com menos quebra de agulhas. (SOPRO e aspiração - limpadores viajantes: tear circular, 2018).

Além disso, é necessário realizar uma supervisão sobre a utilização dos EPI’s exigidos para a função exercida.

\subsection{PROBLEMA 2 - QUEBRA FREQUENTE DE AGULHAS}

O primeiro problema observado é que cada operador possui duas máquinas sob sua constante supervisão. Ao quebrar uma agulha ou arrebentar um fio, geram-se defeitos na peça, causando o desperdício de material e da mão-de-obra. Percebe-se a preocupação com falhas na produção causadas pela quebra de agulhas; buscam-se, então, soluções que demonstrem, mais rapidamente, o momento em que a agulha é quebrada para logo ser substituída e, assim, não causar danos ao material produzido.

Solução: é sugerida a colocação de máquinas com sensores que possibilitem pausar o funcionamento ao arrebentar o fio ou ao quebrar agulhas. Sendo assim, o operário não se preocuparia em observar esses problemas, isto é, o defeito seria evitado imediatamente, necessitando menos retrabalho. O sensor sugerido é o Sensor de Agulha Digital 4022 com exibição de posição da agulha como mostra a figura 9.

Figura 9 - Sensor de agulha digital 4022 com exibição de posição de agulha

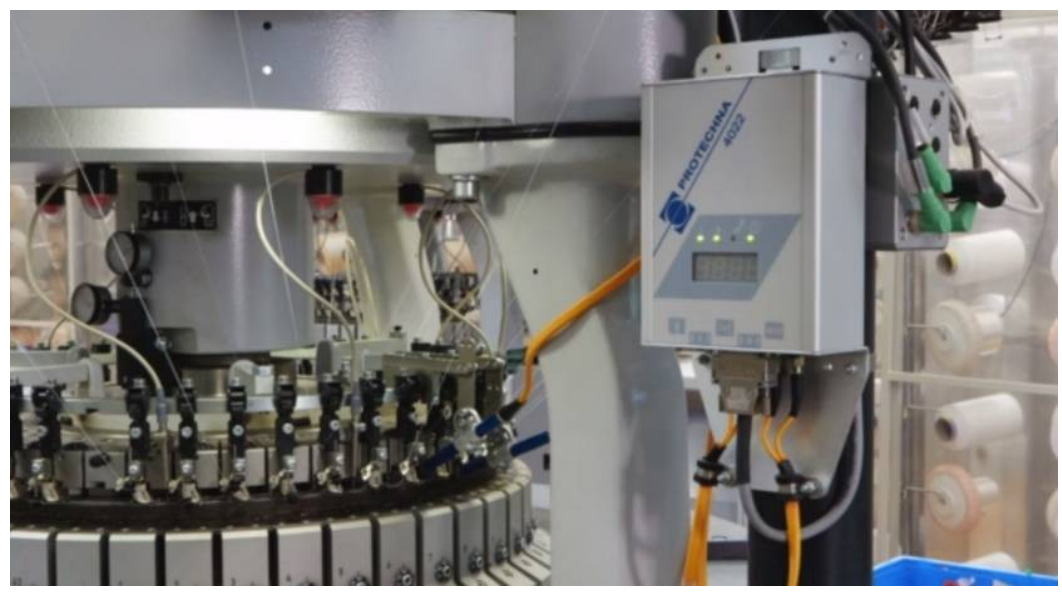

FONTE: Needle sensor 4022 (2018).

Descrição do Sensor de Agulha Digital 4022 com exibição de posição da agulha:

A máquina pausa, imediatamente, assim que as agulhas defeituosas são reconhecidas. Cabeça óptica projeta um ponto estreito de luz nos 
ganchos de agulhas que passam, o que reflete uma parte da luz. Esses pulsos de luz são alimentados para a unidade de controle através de um cabo de fibra óptica. A unidade de controle adapta-se, automaticamente, à sequência da agulha correspondente à velocidade da máquina e ao calibre das agulhas. Se um pulso não for recebido devido à quebra da agulha, o controle da máquina é acionado para parar. Simultaneamente com o sinal de parada, um contador de agulhas começa a funcionar. Isso indica o número de agulhas que correm até a parada da máquina atual. Isso simplifica a localização e a substituição das agulhas defeituosas. As agulhas que faltam para produzir linhas separadoras ou para criar padrões são mascaradas. Como recurso adicional contra paradas falsas, o número de repetições de falhas antes de parar a máquina é ajustável. (NEEDLE sensor 4022, 2018, tradução nossa)

\subsection{PROBLEMA 3 - INSPEÇÃO DO MATERIAL PRODUZIDO}

O próprio operador analisa, visualmente, a peça e, ao mesmo tempo, esse operador deve inspecionar duas máquinas. Ao ocorrer um problema em uma das máquinas, esse só é percebido momentos depois. Desse modo, pode ocorrer uma grande perda de material produzido.

Solução: a inspeção do procedimento atual é visual. O próprio operador inspeciona a peça feita. Diante disso, o funcionário pode acobertar os possíveis problemas e defeitos na produção de forma a não receber punições verbais, estando na frente dos outros funcionários. Deve-se ter uma única pessoa responsável para que a qualidade seja garantida e as perdas sejam minimizadas. Com isso, conseguimos reorganizar as funções do processo produtivo para o modelo a seguir (figura 10), levando em consideração a utilização do sensor de agulha digital e a máquina de sopro e aspiração para a limpeza automática, citados como soluções dos problemas acima comentados.

Figura 10 - Modelo de distribuição de funções, levando em consideração a utilização do sensor de agulha digital e a máquina de sopro e aspiração para a limpeza automática

Operador 1: Supervisão de 4 máquinas e colocação dos fios

Operador 2: Supervisão de 4 máquinas e colocação dos fios

Operador 3: Estocagem dos produtos e matéria prima e retirada do produto acabado das máquinas

Supervisor: Inspeção do material acabado e programação da produção

FONTE: A autora (2018).

Com isso, as funções ficam bem mais definidas e cada funcionário assume funções específicas para vencer a monotonia e manter-se sempre ocupado, sem o acobertamento de falhas por parte do responsável pelo defeito. Na figura 11, pode-se observar o diagrama de 
Gantt para o sistema atual e para a divisão das funções propostas e a inclusão das máquinas citadas. Deve-se levar em conta que cada retângulo representa 10 minutos.

Figura 11 - Gráfico de Gantt para o sistema oficial

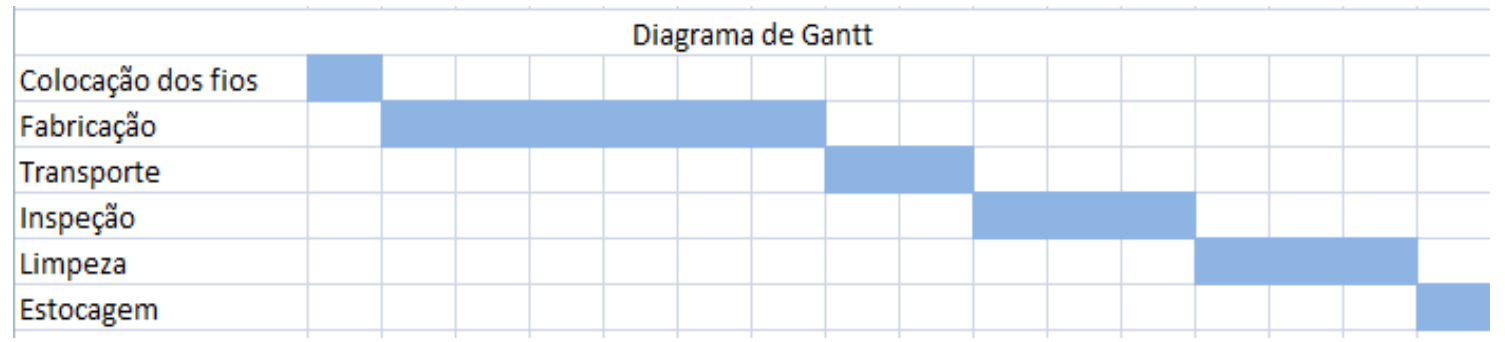

FONTE: A autora (2018).

Com isso, o Gráfico de Gantt para a forma de divisão das funções fabris proposta ficaria conforme a figura 12:

Figura 12 - Gráfico de Gantt para a divisão de funções propostas e inclusão das máquinas

\begin{tabular}{l|l|l|l|l|l|l|l|}
\hline \multicolumn{3}{|c|}{ Diagrama de Gantt } \\
\hline Colocação dos fios & & & & \\
\hline Fabricação & & & & \\
\hline Transporte & & & & \\
\hline Inspeção & & & & \\
\hline Limpeza & & & & & \\
\hline Estocagem & & & & & \\
\hline
\end{tabular}

FONTE: A autora (2018).

Como o planejamento da produção e a estocagem da matéria-prima são feitas apenas uma vez por mês, não foram levadas em conta na elaboração deste diagrama. Com a inclusão das máquinas, a reestruturação das funções e a exclusão do tempo de setup, temos a redução de cerca de 18,75\% do tempo total de produção de cada rolo. O tempo atual é cerca de 160 minutos (2 horas e 40 minutos) e, com a implantação do projeto de melhoria, o tempo passa para cerca de 130 minutos (2 horas e 10 minutos) por rolo.

O tempo atual foi obtido com a medição de um cronômetro, excluindo somente o período de limpeza, visto que não será necessário contar, pois a máquina de aspiração e de sopro fará a limpeza de forma completa sem gasto da mão de obra.

\section{CONCLUSÃO}

No mundo atual, a redução de desperdícios torna-se imprescindível para a obtenção de preços competitivos, de forma a manter as empresas no mercado. 
Em resposta à primeira pergunta da pesquisa, pode-se perceber que há um desperdício muito grande com os movimentos desnecessários, a falta de cuidados com a ergonomia e o meio ambiente, que podem gerar absenteísmo da mão de obra ou mesmo doenças ocupacionais e entre os principais problemas, o tempo ocioso.

Quanto ao processo de produção, os agentes químicos foram identificados como um dos problemas que mais contribuem para afetar a produção e a saúde dos trabalhadores. Dois tópicos chamam atenção quando citamos os agentes químicos. O primeiro refere-se ao desperdício de movimento dos operários em relação ao tempo que eles levam para realizar a limpeza. O segundo aborda os efeitos dos agentes na saúde do colaborador. No sistema atual, os “restos de algodão” permanecem no ar e podem ser inalados, causando doenças ocupacionais. Deve-se notar também que no modelo atual de limpeza utiliza-se água e, por haver tomadas de eletricidade no local sem as devidas proteções, podem gerar riscos de curtos-circuitos elétricos.

Com isso, mostrou-se extremamente necessário realizar a inclusão de dispositivos, tais como máquinas de sopro e aspiração automática. Pois, primeiramente, o operário não precisaria desperdiçar tempo e movimentação limpando a máquina e, segundo, realizar-se-ia uma aspiração completa dos detritos de algodão que ficassem espalhados pelo ar, sem prejudicar a saúde do trabalhador, além de manter o ambiente produtivo sempre limpo. Deve-se levar em conta que ambos podem afetar a saúde física do trabalhador.

A quebra frequente de agulhas gera um elevado custo de produção devido aos desperdícios, porque além da necessidade de reposição das mesmas, gerando perda financeira, ela gera tempo ocioso com setup. Além disso, se o operador não observar que a agulha quebrou-se, a mesma pode causar rasgos no material fabricado. A solução encontrada foi a inclusão de sensores de agulha digital 4022 com a exibição de posição da agulha. Os sensores fazem a máquina parar automaticamente quando ocorre a quebra de uma agulha e mostram a sua posição no momento do seu rompimento, aumentando a rapidez, a realização da sua troca e evitando que ocorram defeitos no material fabricado.

Em resposta à segunda pergunta da pesquisa, para a melhoria seria necessário proceder a inclusão de sensores de agulha digital e da máquina de sopro e aspiração para limpeza automática, o que faz parte do projeto de reorganização e otimização das atividades que ocorrem na Fábrica. Com a instalação desse maquinário, estimamos uma eliminação de $18,5 \%$ do tempo total de produção, o que corresponde a aproximadamente 30 minutos. A aquisição do maquinário pode gerar um custo alto em curto prazo, porém em longo prazo 
obtém-se o retorno do investimento apenas com o aumento das vendas devido à possibilidade de aumento da produção.

Se as propostas de melhoria forem implementadas, os lucros tendem a aumentar, visto que diminuirá a quantidade de agulhas quebradas e peças defeituosas. Com isso, melhorará também a qualidade e a quantidade de produtos fabricados e, além disso, serão prevenidos problemas com a saúde dos operários. Com o aumento do bem estar e da qualidade de vida no trabalho, os empregados ficarão mais motivados e isso torna-se fundamental nos dias atuais.

Ressalta-se, entretanto, que as soluções sugeridas não levaram em consideração os custos de inclusão de cada melhoria. Essa análise será feita, posteriormente, sobre a viabilidade econômica e a prioridade da implantação das mesmas.

\section{REFERÊNCIAS BIBLIOGRÁFICAS}

[1] CARVAlHO, Elvis Marcio Pereira de et al. Aplicação da Filosofia Kaizen no Chão de Fábrica de uma Indústria de Biscoitos. XXXVII Encontro Nacional de Engenharia de Produção. Joinville. 2017.

[2] CAUCHICK, M. P. A. et al. Metodologia de pesquisa em engenharia de produção e gestão de operações. 2 ed. Elsevier: Rio de Janeiro, 2012.

[3] CHEGAR a caixas de rolo de malha de arame com rodas carrinho de paletes para a logística de armazém. Alibaba.com. Disponível em:<https://portuguese.alibaba.com/ p-detail/reach-warehouse-wire-mesh-wheeled-roll-pallet-cart-for-logistics-crates60433001523.html>. Acesso em: 17 mar. 2018.

[4] DRESCH, A.; DIEnStMAnN, G. H.; CASSEL, R. A. Princípios da produção enxuta em curtumes. XXXI Encontro Nacional de Engenharia de Produção. Belo Horizonte. 2011.

[5] EYNG, Mariana Peruchiet al. Aplicação da Filosofia Lean Manufacturing em uma Empresa de Acabamentos de Confecção no Sul de Santa Catarina. XXXVII Encontro Nacional de Engenharia de Produção. Joinville. 2017.

[6] EXTRACÇÃO localizada: montagem de sistema de ventilação localizada em sala de laboratório.

Duoventila.

Disponível

em: $<$ http://www.duoventila.pt/completenew.php?cod noticia=2288\&cod=5 $>$. Acesso em: 21 mar 2018. 
[7] GONCALVES, Renato; LUZ, Marta. Proposta de Implantação de Ferramentas de Qualidade no Processo Produtivo de uma Empresa Alimentícia. XXXVI Encontro Nacional de Engenharia de Produção. João Pessoa. 2016.

[8] HIRANO, H. JIT Implementation Manual Second Edition: JIT Management Laboratory Company.Tokio, 1989.

[9] IIDA, I. Ergonomia, projeto e produção. São Paulo: Edgard Blucher, 2002.

[10] PHELIPE, Bruno; JUNIOR, Walther. Análise dos Resultados do Projeto de Implantação do Lean Manufacturing em uma Empresa Fabricante de Máquinas Agrícolas: Um Estudo de Caso. XXXVII Encontro Nacional de Engenharia de Produção. Joinville. 2017.

[11] SCHEUnEMAnN, Rafael et al. Análise e Redução de Perdas em uma Indústria Têxtil. XXXIV Encontro Nacional de Engenharia de Produção. Curitiba. 2014.

[12] SLACK, N., CHAMBERS, S., JOHNSTON, R., Administração da Produção. 2 ed. São Paulo: Editora Atlas, 2002.

[13] SLACK, N; CHAMBERS, S; JOHNSTON, R; BETTS, A. Gerenciamento de operações e de processos: Princípios e prática de impacto estratégico. Porto Alegre: Bookman 2008.

[14] SILVA; V. SANTOS, S. Aplicação do Programa 5S para Otimização de uma Linha de Produção de Biscoitos numa Fábrica de Massas. Simpósio de Pesquisa Operacional da Marinha. 2015

[15] SOPRO e aspiração - limpadores viajantes: tear circular. Stemmann. Disponível em:

[16] $\quad<$ http://www.stemmann.com.br/produtos/sopro-e-aspiracao-limpadoresviajantes/tear-circular>. Acesso em: 17 mar. 2018.

[17] TAYLOR, F. W. Princípios de administração científica. 7 ed. São Paulo: Editora Atlas,1970. 